\title{
A meta-analysis of inpatient treatment outcomes of severe acute malnutrition and predictors of mortality among under-five children in Ethiopia
}

Fasil Wagnew ${ }^{1 *}$, Getenet Dessie ${ }^{6}$, Wubet Worku Takele $^{3}$, Aster Tadesse $^{1}$, Sheikh Mohammed Shariful Islam², Henok Mulugeta ${ }^{1}$, Dessalegn Haile ${ }^{1}$, Ayenew Negesse ${ }^{1}$ and Amanuel Alemu Abajobir ${ }^{4,5}$

\begin{abstract}
Background: Severe forms of malnutrition have drastic effects on childhood morbidity and mortality in sub-Saharan countries, including Ethiopia. Although few studies have previously estimated treatment outcomes of severe acute malnutrition (SAM) in Ethiopia, the findings were widely varied and inconsistent. This study thus aimed to pool estimates of treatment outcomes and identify predictors of mortality among children with SAM in Ethiopia.

Methods: A systematic review was carried out to select 21 eligible articles from identified 1013 studies (dating from 2000 to 2018) that estimated treatment outcomes and predictors of mortality among SAM children. Databases including PubMed, CINHAL, Web of Sciences; Cochrane, Psych INFO and Google Scholar were comprehensively reviewed using medical subject headings (MESH) and a priori set criteria PRISMA guideline was used to systematically review and meta-analyze eligible studies. Details of sample size, magnitude of effect sizes, including Hazard Ratio (HRs) and standard errors were extracted. Random-effects model was used to calculate pooled estimates in Stata/se version14. Cochran's $Q, I^{2}$, and meta-bias statistics were assessed for heterogeneity and Egger's test for publication bias.

Result: Twenty-one studies were included in the final analysis, which comprised 8057 under-five children with SAM in Ethiopia. The pooled estimates of treatment outcomes, in terms of death, recovery, defaulter and transfer out and nonresponse rates were 10.3\% (95\% Cl: 8.3, 12.3), 70.5\% (95\% Cl: 65.7, 72.2), 13.8\% (95\% Cl: 10.8, 16.9) and 5.1\% (95\% Cl: 3.3, 6.9), respectively. Diarrhea (HR: 1.5, 95\% Cl: 1.1, 2.2), dehydration (HR: 3.1, 95\% Cl: $2.3,4.2$ ) and anemia (HR: 2.2, 95\% Cl: $1.5,3.3)$ were statistically significant predictors of mortality among these children. No publication bias was detected.

Conclusion: Treatment outcomes in under-five children with SAM are lower than the World Health Organization (WHO) standard, where mortality is being predicted by comorbidities at admission. Children with SAM need to be treated for diarrhea, dehydration and anemia at the primary point of care to reduce mortality.
\end{abstract}

Keywords: Severe acute malnutrition, Treatment outcomes, Meta-analysis, And Ethiopia

\footnotetext{
* Correspondence: fasilw.n@gmail.com

${ }^{1}$ College of Health Science, Debre Markos University, Debre Markos, Ethiopia

Full list of author information is available at the end of the article
}

(c) The Author(s). 2019 Open Access This article is distributed under the terms of the Creative Commons Attribution 4.0 International License (http://creativecommons.org/licenses/by/4.0/), which permits unrestricted use, distribution, and reproduction in any medium, provided you give appropriate credit to the original author(s) and the source, provide a link to the Creative Commons license, and indicate if changes were made. The Creative Commons Public Domain Dedication waiver (http://creativecommons.org/publicdomain/zero/1.0/) applies to the data made available in this article, unless otherwise stated. 


\section{Background}

Globally, an estimated 20 million under-five children suffer from severe acute malnutrition (SAM) contributing to 1 million deaths every year, mainly attributable to comorbid and/or consequent infections [1, 2]. SAM is characterized by two clinical parameters: (1) severe wasting; that is, marasmus, defined as middle upper arm circumference (MUAC) $<115 \mathrm{~mm}$ for children aged $>6$ months or a weight-for-height $<-3 \quad$ z-scores according to WHO's growth standards for under-five children; and (2) nutritional edema with kwashiorkor; that is, the presence of clinically confirmed bilateral, pitting edema [2-4].

Acute malnutrition is a major challenge for achieving sustainable development goals (e.g., Goals 2 and 3-Zero Hunger and Good Health and Wellbeing) as it is associated with major causes of under-five mortality. Moreover, it leads to adverse maternal and child health consequences including retarded school performance and aggravating maternal related problems $[5,6]$ especially in poorer settings. For instance, $2 \%$ of children (nearly 13 million) suffer from SAM in developing countries [7] of which over 90\% live in South- East Asia and sub-Saharan Africa [8]. Indeed, SAM is a common indication for pediatric hospital admission and inpatient treatment in these countries. Thus, mortality of children from SAM in inpatient set-ups in sub-Saharan Africa still remains significantly high, with ten-folds higher the risk of death than well-nourished children [9].

Ethiopia has a long history of food insecurity and nutritional disorders aggravated by larger population size, land degradation, and droughts affecting a larger proportion of population $[4,10,11]$. Consequently, the country has been experiencing malnutrition related problems, although both community- and facility-based interventions are in place. For instance, children with SAM had conventionally been managed according to WHO standard in facility set-ups encompassing admission and comprehensive inpatient clinical treatment, although this protocol was first published in 1999 [12] and has guided only inpatient care of complicated SAM patients. Recently (2013 to date), there has been a paradigm shift for treating SAM, using updated WHO treatment guideline published in 2013, with compressive approaches [13]. This includes inpatient, outpatient, and communitybased management of acute malnutrition (CMAM) and also provides training for health workers. The main aim of this approach is to decrease over crowdedness by treating non-complicated SAM cases at outpatient treatment programmes (OTP) without admitting to a hospital [7]. Adhering to this protocol has enhanced desired treatment outcomes $[14,15]$.

In Ethiopia, the health sector has attempted to upgrade nutritional intervention and improve treatment outcomes through health promotion, effective treatment strategy and supplementation of essential micronutrients for children and mothers. Different small scale fragmented studies have been conducted to determine treatment outcomes of children with SAM. However, the evidence base from previous studies on the treatment outcomes of, and factors associated with, SAM are inconsistent, and remain inconclusive. That is, under-five mortality rate in children with SAM ranges from $3.5 \%$ [16] to $29 \%$ [17] in Ethiopia, depicting a $26 \%$ variation between studies. Similarly, recovery rate ranges from $43.5 \%$ [16] to 87.6 [18] in different facilities of the country. This suggests that prevention and management of SAM are not uniform and unfinished agendas across the country may be because of lack of access to relevant healthcare, inconsistence use of SAM treatment protocol, etc. In addition, predictors of treatment outcome, particularly mortality, have not been well addressed, although anemia, HIV/AIDS, tuberculosis and diarrhea are reported to be some predictors of time to death [16, 19-23].

The main aim of the current meta-analysis is to determine treatment outcomes and predictors of mortality among under-five children with SAM in Ethiopia. This will assist decision makers and/or other stakeholders to practice effective and efficient SAM management.

\section{Methods \\ Design}

This is a systematic review and mata-analysis of published articles on SAM in Ethiopia using a priori criteria.

\section{Search strategies}

To identify relevant articles, four authors (FW, GD, HM, and AAA) systematically searched for studies published in English from 2000 to 2018 in PubMed, Web of Science, Cochrane library, Embase, Cumulative Index to Nursing and Allied Health Literature (CINAHL) and Google scholar. Reference lists and grey literature such as programme reports were also retrieved. We used medical subject headings (MESH), adding terms and keywords from a primary search to formulate search strategy in these databases. In all databases, we utilized an interactive process to improve the search strategy through checking numerous search terms and including new search terms as new relevant citations were identified. The keywords included: 'epidemiology', 'treatment outcome', 'inpatient severe acute malnutrition', 'under-five', 'children', 'predictors', 'associated factors' and 'Ethiopia'. Boolean operators - 'OR' or 'AND' - were used. Endnote reference manager software was used to collect and organize search outcomes and for removal of duplicate and /or irrelevant articles.

\section{Eligibility criteria}

Studies conducted in Ethiopia, reporting inpatient treatment outcomes of SAM among under-five children, all 
published and unpublished observational study designs (i.e., cross-sectional, case-control and cohort) were included. Included studies were within the PICO framework $(P=$ under-five children with SAM; I = SAM management; $\mathrm{C}=$ under-five children with no selected SAM treatment outcomes; $\mathrm{O}=$ under-five children with selected SAM treatment outcomes). Articles with no full text, after email contact with the primary author, and those studies reporting outcomes above the age of 5 were excluded.

\section{Measurement of outcome variables}

The outcomes of interest included the proportion of treatment outcomes of SAM, and predictors of mortality among under-five children with SAM. For predictors, Hazard Ratio (HR) was calculated for dichotomous outcomes from the primary studies. Those predictors included in this study were: sex ('male' versus 'female'), diarrhea ('no' versus 'yes'), dehydration ('no' versus 'yes'), and anemia ('no' versus 'yes').

\section{Data extraction}

Data extraction format was constructed and pilot-tested with a subset of eligible studies, and then summarized using a table. Two reviewers (FW, HM) independently extracted necessary information from relevant articles. Discrepancies were adjudicated or discussed with a third reviewer (AN), whenever appropriate. We made some efforts to communicate the authors whenever further information was required. Numerator and denominator data and beta coefficients and their standard errors (if given) were used to compute HRs, where HRs with 95\% CI were not reported. For dichotomous data, we extracted the number of participants with the outcome and the total sample size. The following study characteristics were extracted: region of the study area, year of publication, participant characteristics, study design, types of hospitals and treatment outcomes.

\section{Risk of bias}

The risk of bias for each relevant article was assessed by two authors (FW and AAA) independently using risk of bias assessment tool. We used the Hoy 2012 addressing internal and external validity tool using 10 criteria [24]. Accordingly, each item has either low or high risk of bias; unclear was categorized as high risk of bias. Overall score of risk of bias was then classified into low, moderate, and high for each eligible study (Additional file 3: Table S1).

\section{Data processing and analysis}

Information about the study design, study sample and country were summarized by Microsoft Excel and then exported to STATA/se version 14 for analysis. Meta-analysis of a pooled proportion of treatment outcomes was carried out using a random-effects model, generating a pooled proportion with 95\% CIs. Heterogeneity across studies was estimated using the Cochran's Q and $\mathrm{I}^{2}$ statistics [25]. The $\mathrm{I}^{2}$ statistic estimates the percentage of total variations across studies that are due to factual betweenstudy differences rather than chance. We also scrutinized forest plots of summary estimates of each study to determine whether we could identify any heterogeneity between studies. For meta-analyses with a minimum of 10 studies, publication bias was determined based on the visual assessment of the funnel plot [26] and Egger's test [27].

\section{Results}

\section{Overview of the search}

This systematic review and meta-analysis has been reported in accordance with the preferred reporting items for systematic reviews and meta-analyses (PRISMA) statement [28]. First, 1013 articles related to the treatment outcomes of children with SAM were found. Of these, 535 duplications and 667 unrelated articles were excluded. Second, from the remaining 39 potential articles, 21 met eligibility for the review and included in the analysis. Eighteen full-text articles were excluded for the following reasons: 8 articles [29-36] due to unmet outcomes of interest or location and 10 studies [37-46] as they focused on outpatient treatment outcomes (Fig. 1).

Kappa statistic was used to measure agreement between reviewers to determine the uniformity of those potentially eligible full-text articles using the guidelines proposed by Landis and Koch [47]: $<0.20$ as slight agreement, $0.21-0.40$ fair agreement, $0.41-0.60$ moderate agreement, $0.61-0.80$ substantial agreement and > 0.80 almost perfect agreement. Finally, the kappa coefficient which revealed the agreement rate between the two reviewers for the included papers was 0.803 .

\section{Descriptive characteristics of the included studies}

We identified and included 21 articles with 8057 participants which offered original data on the treatment outcomes of SAM among under-five children in Ethiopia. Main characteristics of the included studies are described in Table 1 . These primary studies used different study designs to examine the magnitude of treatment outcomes of SAM. Thirteen out of 21 (61\%) studies were retrospective cohort and the remaining 8 (39\%) were cross-sectional in design. Sample size ranged from 151 [43] to 947 [48]. Reported under-five mortality rate ranged from $3.5 \%$ [16] to $29 \%$ [17]. Similarly, the recovery rate ranged from $43.5 \%$ [16] to $87.6 \%$ [18]. Defaulter rate ranged from $2.6 \%$ [49] to $43.6 \%$ [16] (Table 1).

\section{Risk of bias assessment}

The risk of bias for each original study was evaluated using toy risk of bias assessment tool which incorporated ten different items [24]. Accordingly, four studies [50-53] had 


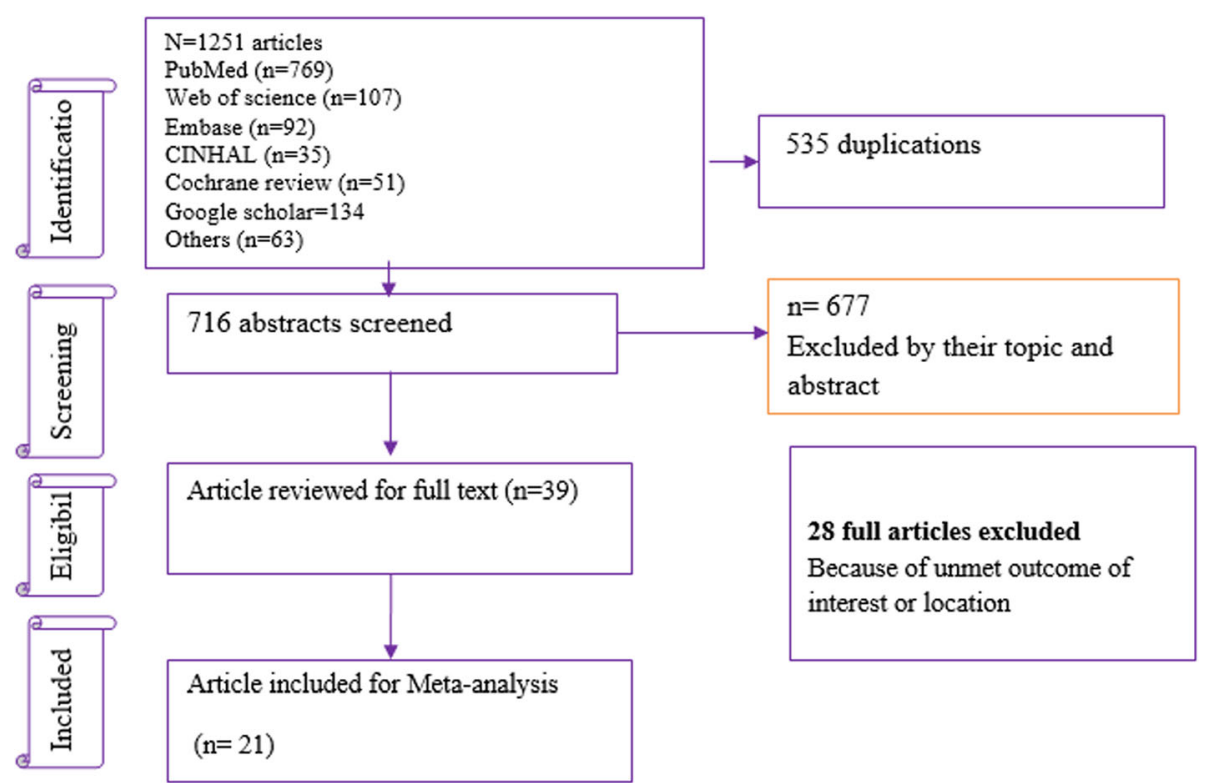

Fig. 1 Flowchart diagram describing selection of studies for a meta-analysis of SAM treatment outcomes among inpatient under-five children in Ethiopia

high risk of bias while ten studies [16-23, 48, 49, 54-58] had low risk of bias and the remaining two studies $[43,59]$ had medium risk of bias (Additional file 3: Table S1). The funnel plot and overall Egger's test for publication bias revealed no statistically significant evidence, $p$-value $=$ 0.23(Additional file 1: Figure S1).

\section{Treatment outcomes of under-five children with SAM}

The pooled mortality rate in 8057 under-five children admitted with SAM was $10.3 \%$ (95\% CI: 8.3, 12.3\%) (Fig. 2). On sensitivity analysis, Kebede et al.,2015 [17], and Tirore et al., 2017 [16] had shown an impact on the overall estimation (Additional file 2: Figure S2).

The pooled estimate of recovery rate, representing 7608 participants admitted to stabilization centers was 70.5\% (95\% CI: 65.7, 72.2) (Fig. 3).

The pooled estimate of defaulter rate, for 21 studies representing 7943 SAM children admitted to stabilization centers was 13.8\% (95\% CI: 10.8, 16.9) (Fig. 4).

Finally, the pooled estimate for transfer out and nonresponse for 13 studies, representing 5098 participants was 5.1\% (95\% CI: 3.3, 6.9) (Fig. 5).

\section{Predictors of SAM treatment outcomes}

Five studies examined the predictors of time to death among SAM children using adjusted statistical models. Statistically significant factors $(p<0.05)$ associated with time to death were reported. In this analysis, diarrhea, dehydration and anemia were significant predictors of mortality among SAM children. As shown in Fig. 6, the risk of mortality was 1.5 times higher for patients with diarrheal comorbidity as compared to those without diarrheal comorbidity (HR: 1.5 (95\% CI: 1.1, 2.2)). Similarly, the likelihood of death was significantly higher in dehydrated patients as compared with those without dehydration (HR: 3.1(95\% CI: 2.3, 4.2)).Finally, the risk of death for SAM children with anemia was more than two times higher than those children without anemia (HR: 2.2(95\% CI: 1.5, 3.3)) (Fig. 6).

\section{Discussions}

This meta-analysis examined treatment outcomes - death, recovery, defaulter and transfer out plus non-response rates - in under-five children admitted to SAM stabilization centers in Ethiopia. The proportion of children that died and recovered does not achieve the minimum SPHERE standard and WHO management protocol for SAM (i.e., $<10 \%$ death rate and $>75 \%$ ) [60]. This high death rate and low recovery rate could be a result of delay at presentation to a stabilization center, the occurrence of recurrent infections, presence of co-morbidities and nonadherence (by healthcare providers) to the current SAM treatment guideline. The finding was also lower than the previous retrospective review done by Teferi et al. $(n=11$, 335 children) that revealed $87 \%$ cure rate and $3.6 \%(n=$ 468) death rate [15]. Likewise, a study from SierraLeone ( $n=1987$ children) reported 83\% recovery rate [61]. This discrepancy might be because of the study characteristics. For instance, previous studies included both moderate and severe forms of acute malnutrition, which might potentially be associated with good treatment outcomes. However, the current analysis reported a recovery rate 
Table 1 Descriptive summary of 21 included studies on treatment outcomes of SAM among under-five children admitted to a stabilization center in Ethiopia

\begin{tabular}{|c|c|c|c|c|c|c|c|c|c|c|}
\hline Authors name & $\begin{array}{l}\text { Publication } \\
\text { year }\end{array}$ & $\begin{array}{l}\text { Study } \\
\text { region }\end{array}$ & $\begin{array}{l}\text { Types of } \\
\text { hospital }\end{array}$ & $\begin{array}{l}\text { Study } \\
\text { design }\end{array}$ & $\begin{array}{l}\text { Age of } \\
\text { participants }\end{array}$ & $\begin{array}{l}\text { Sample } \\
\text { size }\end{array}$ & $\begin{array}{l}\text { Death rate } \\
(\%)\end{array}$ & $\begin{array}{l}\text { Recovery } \\
\text { rate (\%) }\end{array}$ & $\begin{array}{l}\text { Defaulter } \\
\text { rate (\%) }\end{array}$ & $\begin{array}{l}\text { Not } \\
\text { recovered } \\
(\%)\end{array}$ \\
\hline Amsalu S [51] & 2006 & Amhara & Referral & $\begin{array}{l}\text { cross } \\
\text { sectional }\end{array}$ & $<59$ months & 335 & 18.2 & 71.6 & 8.9 & - \\
\hline $\begin{array}{l}\text { G/Michael et } \\
\text { al. [20] }\end{array}$ & 2014 & Tigray & Referral & cohort & 6-59 months & 469 & 12.8 & 69.7 & 12.1 & 5.9 \\
\hline $\begin{array}{l}\text { Chane et al. } \\
\text { [59] }\end{array}$ & 2014 & Amhara & Others & $\begin{array}{l}\text { cross } \\
\text { sectional }\end{array}$ & $<59$ months & 324 & 6 & 84.8 & 4.9 & 4.0 \\
\hline Ahmed M [82] & 2014 & $\begin{array}{l}\text { Addis } \\
\text { Ababa }\end{array}$ & Referral & $\begin{array}{l}\text { cross } \\
\text { sectional }\end{array}$ & 6-59 months & 193 & 12.4 & 75.1 & 12.4 & - \\
\hline $\begin{array}{l}\text { Misganaw C } \\
{[18]}\end{array}$ & 2014 & Oromia & Referral & $\begin{array}{l}\text { cross } \\
\text { sectional }\end{array}$ & $<59$ months & 173 & 5.7 & 87.6 & 6.9 & - \\
\hline $\begin{array}{l}\text { Wegen S. et al. } \\
\text { [43] }\end{array}$ & 2015 & SNNP & Referral & $\begin{array}{l}\text { Cross- } \\
\text { sectional }\end{array}$ & $<59$ months & 151 & 15.2 & 69.5 & 15.2 & - \\
\hline $\begin{array}{l}\text { Delelegn Y } \\
\text { [58] }\end{array}$ & 2015 & SNNP & Others & cohort & 6-59 months & 420 & 9.3 & 82.3 & 5.7 & 2.6 \\
\hline Kebede S [17] & 2015 & Amhara & Others & cohort & $<59$ months & 415 & 29 & 46.9 & 20.9 & 2.9 \\
\hline Jarso et al. [48] & 2015 & Oromia & Referral & cohort & $<59$ months & 947 & 9.3 & 77.8 & 12.8 & - \\
\hline Tadele, [54] & 2016 & SNNP & Referral & cohort & $<59$ months & 449 & 12.4 & - & - & - \\
\hline Firehiwot [57] & 2016 & $\begin{array}{l}\text { Dire- } \\
\text { Dawa }\end{array}$ & Referral & cohort & $<59$ months & 617 & 7.6 & 69.8 & 14.2 & 11.2 \\
\hline $\begin{array}{l}\text { Abeje et al. } \\
\text { [52] }\end{array}$ & 2016 & Amhara & Referral & $\begin{array}{l}\text { cross } \\
\text { sectional }\end{array}$ & $<59$ months & 298 & 11.7 & 68.4 & 19.8 & - \\
\hline $\begin{array}{l}\text { Mekuria et al. } \\
\text { [22] }\end{array}$ & 2017 & Amhara & Others & cohort & 6-59 months & 253 & 5.5 & 77.8 & 12.2 & 4.3 \\
\hline Kabeta A [49] & 2017 & SNNP & Others & cohort & $<59$ months & 191 & 16 & 78.0 & 2.6 & 3.1 \\
\hline $\begin{array}{l}\text { Wagnew et al. } \\
\text { [23] }\end{array}$ & 2017 & Amhara & Referral & cohort & $<59$ months & 527 & 12.52 & 67.7 & 17.8 & 1.9 \\
\hline $\begin{array}{l}\text { Desyalew et al. } \\
\text { [55] }\end{array}$ & 2017 & Amhara & Referral & $\begin{array}{l}\text { cross } \\
\text { sectional }\end{array}$ & 6-59 months & 401 & 8.5 & 76.8 & 12.9 & 0.5 \\
\hline Girum, [21] & 2017 & SNNP & Others & cohort & $<59$ months & 545 & 9.3 & 76.1 & 4.7 & 9.7 \\
\hline $\begin{array}{l}\text { Admasu A, et } \\
\text { al. [56] }\end{array}$ & 2017 & SNNP & Referral & cohort & $<59$ months & 340 & 8.8 & 75.5 & 10 & 5.6 \\
\hline $\begin{array}{l}\text { Tirore et al. } \\
\text { [16] }\end{array}$ & 2017 & Amhara & Referral & $\begin{array}{l}\text { cross } \\
\text { sectional }\end{array}$ & $<59$ months & 195 & 3.5 & 43.5 & 43.6 & 9.2 \\
\hline Asres et al. [19] & 2018 & Amara & Referral & cohort & $<59$ months & 401 & 4.2 & 51.8 & 35.6 & 8.2 \\
\hline $\begin{array}{l}\text { Behilu T et al. } \\
\text { [50] }\end{array}$ & 2018 & Amhara & Others & cohort & $<59$ months & 413 & 5.8 & 55.9 & 16.2 & - \\
\hline
\end{tabular}

SNNP=Southern Nations, Nationalities, and Peoples

higher than that reported in Indian study (1130 SAM children) where $51.7 \%$ children were discharged from the program upon meeting discharge criteria [62]. Interestingly, the defaulter rate was in parallel with SPHERE report standard stating that the defaulter rate should be less than $15 \%$ [60]. By contrast, this finding was lower than a finding in India $(47.2 \%$ children did not complete their treatment course - defaulters) [62]. The observed variation might be due to sociodemographic characteristics, study period and provision of quality of care, or inefficient use of resources including manpower. Moreover, uncomplicated SAM has occasionally been admitted to Asian stabilization centers [63].

In terms of predictors of mortality in SAM children, the association of diarrhea and SAM is a well-recognized fact $[64,65]$, although, to the best of our knowledge, the management of children presenting with diarrhea and SAM is limited [66]. This could have a vital role for treatment outcomes. This is supported by several studies [67-71] that have shown increased mortality rates in children who have both diarrhea and SAM comorbidities. This possibly is attributed by the fact that children 


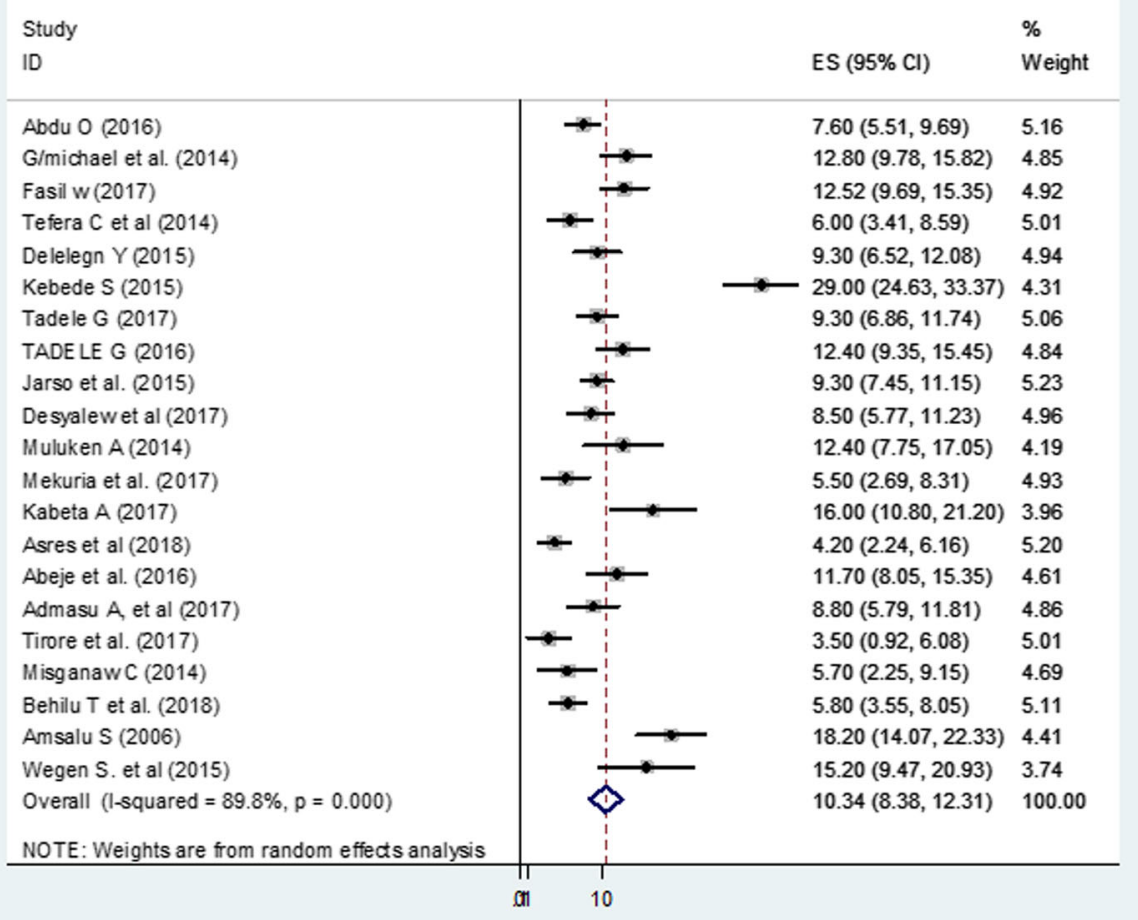

Fig. 2 Forest Plot of the 21 studies estimating the mortality rate of under-five children with SAM in Ethiopia

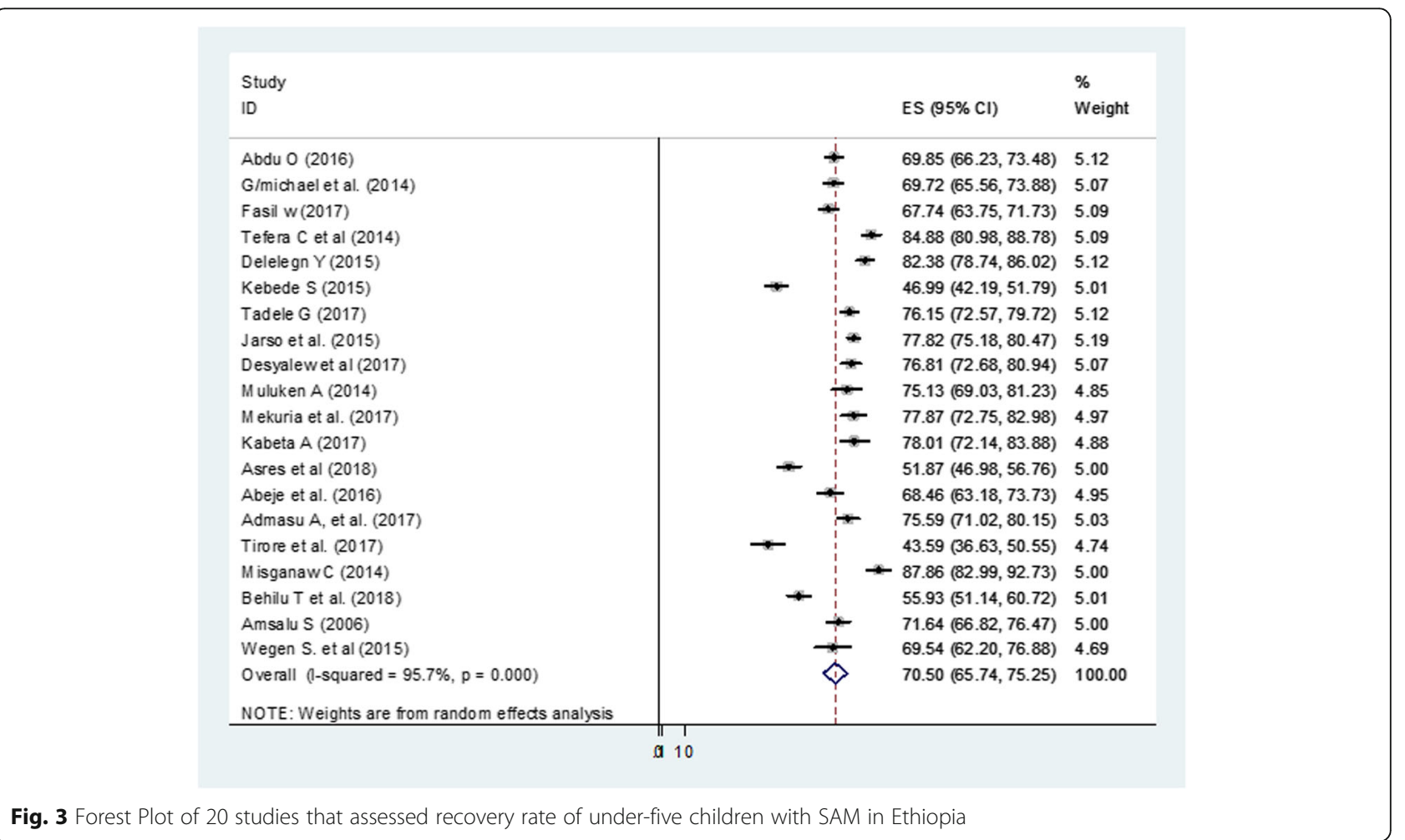




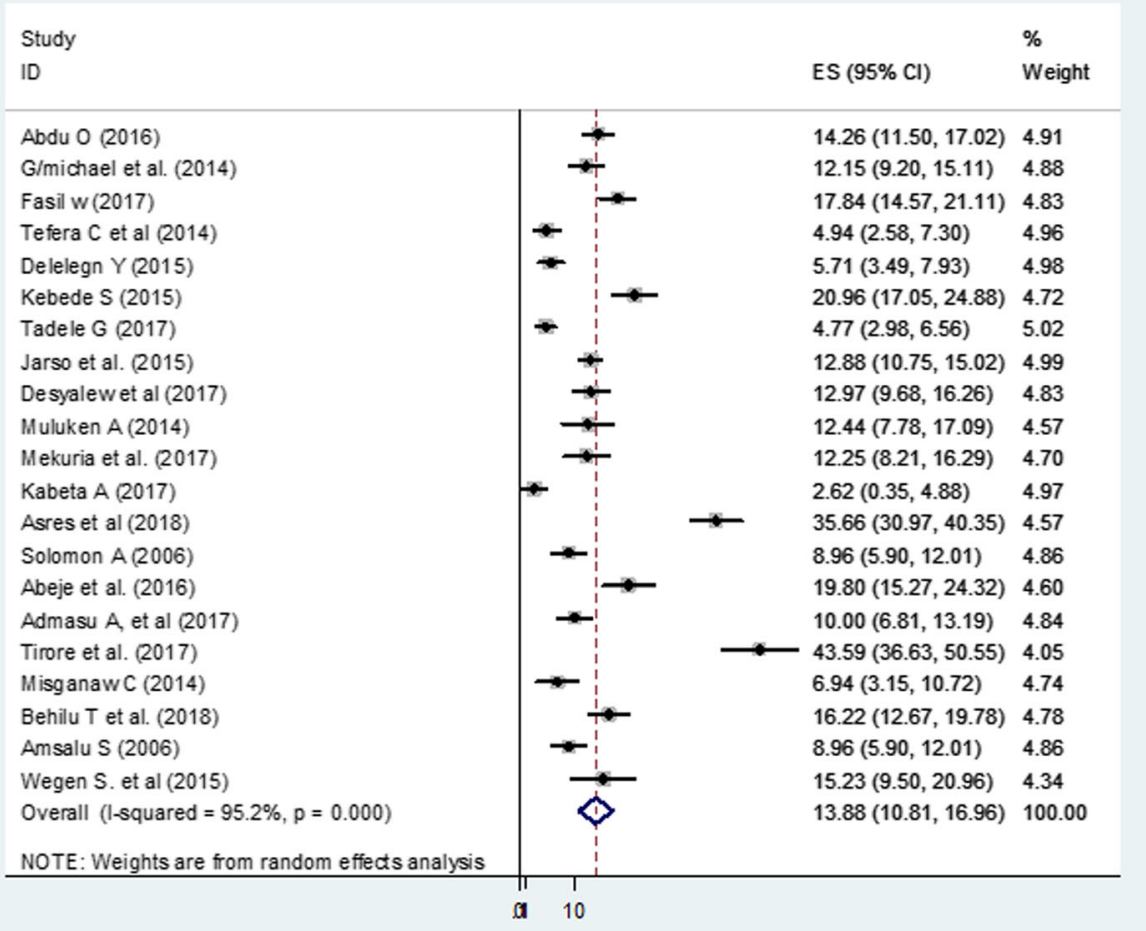

Fig. 4 Forest Plot for 21 studies that reported defaulter rate among under-five SAM children in Ethiopia

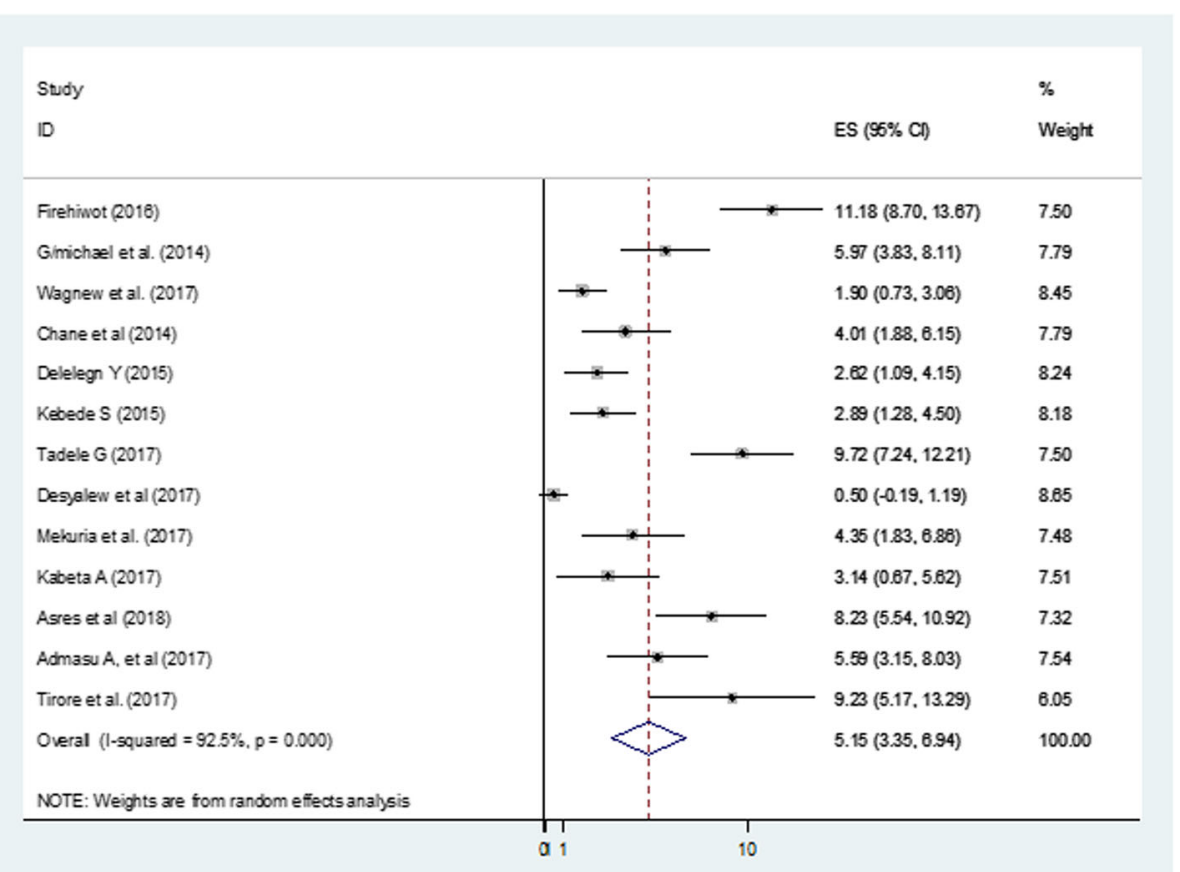

Fig. 5 Forest Plot of 13 studies reporting the proportion of non-recovery and transfer out among under-five SAM children in Ethiopia 


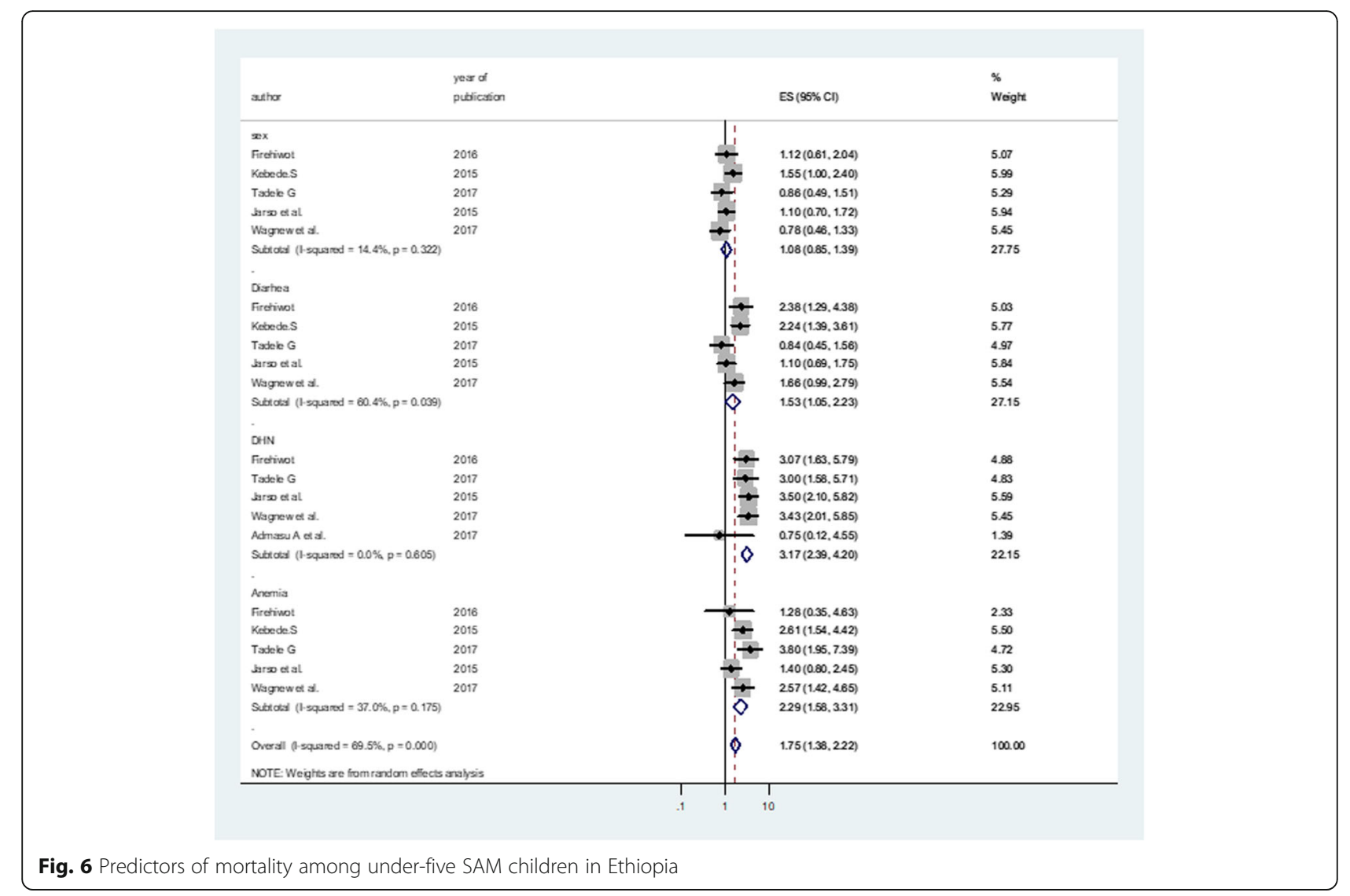

with diarrhea have concurrent clinical features including severe dehydration, impaired perfusion, and severe metabolic acidosis that would raise mortality. Moreover, gram-negative bacteremia is normally allied with diarrhea and is the major risk factor for death, nonetheless of HIV or anthropometric status [72].

Furthermore, higher mortality rates amongst dehydrated children is likely to be related to the fact that children develop metabolic disturbance and volume deficit with the high prevalence of bacterial disease. Furthermore, the urgent correction of hypotension by speedy volume expansion may attribute to potential sodium and fluid overload that could be a plausible subsidizing factor to death [73-75]. We also found that anemia is one of the predictors responsible for increased mortality in SAM children. Consistently, the risk of earlier death for anemic children is reported to be significantly higher than for children without anemia $[14,76,77]$. The higher risk of mortality is because of an increased prevalence of infection and increased probability of heart failure [78].

Enhancing management of inpatient SAM remains an important approach for reducing malnutrition-related complications including mortality. As such, rendering comprehensive outpatient treatment for most SAM patients may diminish inpatient caseloads, decreases the risks of hospital-acquired infections, and thus, leave staff time to inpatient care. This strategy may reduce case-fatality rates, with cost-effective techniques. Indeed, this is recommended by updated WHO SAM management guideline which is meant to be adhered and implemented in respective set ups.

In general, our findings have policy implications for the management of children with SAM. Policymakers should be cognizant of this to strengthen health systems for appropriate management of SAM. Accordingly, in a bid to improve treatment outcomes for children with SAM, the WHO developed a-ten steps guideline for effective management of SAM, which is a widely accepted standard [79]. Indeed, few studies have reported the feasibility and sustainability of the implementation of this guideline in district hospitals with insufficient resources [80, 81]. Thus, further evaluation studies may fill this gap.

However, the findings need to be considered in the context of some important limitations. These included less control for possible confounders as crude hazard ratios were used to estimate some factors associated with treatment outcomes as opposed to adjusted analyses due to scarcity of data. Moreover, although Egger's test did not show any risk of publication bias, few studies (e.g., 
Kebede et al., 2015 and Tirore et al., 2017)) showed high heterogeneity that needs to be considered while interpreting these findings.

\section{Conclusion}

Desired treatment outcomes in under-five children with SAM are lower than the WHO standard, where mortality is being predicted by comorbidities at admission. Healthcare facilities and providers are strongly advised to adhere to and implement based on the up-to-date inpatient SAM treatment and management protocol.

\section{Additional files}

Additional file 1: Figure S1. Funnel plots, exploring publication bias for the analysis of pooled estimate (PNG $456 \mathrm{~kb}$ )

Additional file 2: Figure S2. The sensitivity analysis showed the pooled mortality when the studies omitted step by step (PNG $2054 \mathrm{~kb}$ )

Additional file 3: Table S1. Risk of Bias assessment Tool of Eligible Articles by using the Hoy 2012 tool (XLSX $13 \mathrm{~kb}$ )

\section{Abbreviations}

HIV/AIDS: Human Immune deficiency virus/Acquired Immune-deficiency Syndrome; HR: Hazard Ratio; SAM: Severe Acute Malnutrition; WHO: World Health Organization

\section{Acknowledgements}

The authors would like to acknowledge the Debre Markos University library for providing us with a wide range of available online databases.

\section{Authors' contributions}

FW involved in the conception of the research idea; (FW, GD, HM, AAA) undertook data extraction, analysis, interpretation, and manuscript write-up. (FW, SMS, AT, DH, WWT, AN, AAA) interpreted the results, data validation and drafted the manuscript. All authors mentioned in the manuscript approved the final manuscript.

\section{Funding}

Not applicable

\section{Availability of data and materials}

All data generated or analyzed during this study are included within the manuscript [and its supplementary information files].

\section{Ethics approval and consent to participate}

Not applicable

\section{Consent for publication}

Not applicable

\section{Competing interests}

The authors declare that they have no competing interests.

\section{Author details}

${ }^{1}$ College of Health Science, Debre Markos University, Debre Markos, Ethiopia. ${ }^{2}$ Institute for Physical Activity and Nutrition (IPAN), Deakin University, Melbourne, Australia. ${ }^{3}$ College of Health Science, University of Gondar, Gondar, Ethiopia. ${ }^{4}$ Faculty of Medicine/school of Public Health, The University of Queensland, Brisbane, Australia. ${ }^{5}$ African Population and Health Research Center, Maternal and Child Wellbeing Unit, Nairobi, Kenya. ${ }^{6}$ College of Health Sciences, Bahirdar University, Bahirdar, Ethiopia.
Received: 25 March 2019 Accepted: 11 August 2019

Published online: 27 August 2019

\section{References}

1. Black RE, Victora CG, Walker SP, Bhutta ZA, Christian P, De Onis M, Ezzati M, Grantham-McGregor S, Katz J, Martorell R. Maternal and child undernutrition and overweight in low-income and middle-income countries. Lancet. 2013; 382(9890):427-51.

2. Organization WH. Pocket book of hospital care for children: quidelines for the management of common childhood illnesses: World Health Organization; 2013. https://www.who.int/maternal_child_adolescent/ documents/child_hospital_care/en/.

3. Organization WH. Guideline: updates on the management of severe acute malnutrition in infants and children: World Health Organization; 2013. https://www.who.int/nutrition/publications/guideline/updates_ management_SAM_infantandchildren/en/.

4. Organization WH, UNICEF: community-based management of severe acute malnutrition: a joint statement by the World Health Organization, the world food Programme, the United Nations system standing committee on nutrition and the United Nations Children's fund. 2007.

5. Senbanjo IO, Oshikoya KA, Odusanya OO, Njokanma OF. Prevalence of and risk factors for stunting among school children and adolescents in Abeokuta, Southwest Nigeria. J Health Popul Nutr. 2011;29(4):364.

6. UNICEF. The state of the world's children 2008: Child survival, vol. 8: UNICEF; 2007 https://www.unicef.org/publications/index_42623.html.

7. Collins S, Sadler K, Dent N, Khara T, Guerrero S, Myatt M, Saboya M, Walsh A. Key issues in the success of community-based management of severe malnutrition. Food Nutr Bull. 2006;27(3_suppl3):S49-82.

8. UNICEF WaWBG. Levels and trends in child malnutrition, joint malnutrition estimates 2012 edition. Washington, DC; 2012. https://www.unicef.org/ media/files/JME_2015_edition_Sept_2015.pdf.

9. Black RE, Allen LH, Bhutta ZA, Caulfield LE, De Onis M, Ezzati M, Mathers C, Rivera J. Maternal, group CUS: maternal and child undernutrition: global and regional exposures and health consequences. Lancet. 2008;371(9608):243-60.

10. IFPRI. The world food situation: new driving forces and required actions. Beijing: Bi-Annual Overview of the World Food Situation presented to the CGIAR Annual General Meeting; 2007.

11. Korthals M. Ethics of food production and consumption. In: The Oxford Handbook of Food, Politics, and Society; 2015. p. 1-15.

12. WHO. Management of severe malnutrition: a manual for physicians and other health workers. Geneva; 1999. http://helid.digicollection.org/en/d/ Jwho77e/

13. WHO. Guideline: updates on the management of severe acute malnutrition in infants and children: World Health Organization; 2013. https://www.ncbi. nlm.nih.gov/books/NBK190328/.

14. Ashworth A, Chopra M, McCoy D, Sanders D, Jackson D, Karaolis N, Sogaula $\mathrm{N}$, Schofield C. WHO guidelines for management of severe malnutrition in rural south African hospitals: effect on case fatality and the influence of operational factors. Lancet. 2004;363(9415):1110-5

15. Teferi $E$, Lera M, Sita S, Bogale Z, Datiko DG, Yassin MA. Treatment outcome of children with severe acute malnutrition admitted to therapeutic feeding centers in Southern Region of Ethiopia. Ethiop J Health Dev. 2010:24(3).

16. Tirore MG, Atey TM, Mezgebe HB. Survival status and factors associated with treatment outcome of severely malnourished children admitted to Ayder referral hospital: a cross-sectional study. BMC Nutrition. 2017;3(1):66.

17. Desta K. Survival status and predictors of mortality among children aged 0 59 months with severe acute malnutrition admitted to stabilization center at Sekota hospital Waghemra zone. J Nutr Disord Ther. 2015;5:160.

18. Misganaw C, Mesfin M, Tesfaye M, Derese A. Retrospective study on outcome of in-patient treatment of severe acute malnutrition in Jimma University specialized hospital from September 2011-September 2012. J Diagn. 2014;1(2):18-28.

19. Asres DT, Prasad RP, Ayele TA. Recovery time and associated factors of severe acute malnutrition among children in Bahir Dar city, Northwest Ethiopia: an institution based retrospective cohort study. BMC Nutrition. 2018;4(1):17

20. Gebremichael M, Bezabih AM, Tsadik M. Treatment outcomes and associated risk factors of severely malnourished under five children admitted to therapeutic feeding centers of Mekelle City, Northern Ethiopia. O A Library J. 2014;1(04):1. 
21. Girum T, Kote M, Tariku B, Bekele H. Survival status and predictors of mortality among severely acute malnourished children $<5$ years of age admitted to stabilization centers in Gedeo zone: a retrospective cohort study. Ther Clin Risk Manag. 2017;13:101.

22. Mekuria G, Derese T, Hailu G. Treatment outcome and associated factors of severe acute malnutrition among 6-59 months old children in Debre Markos and Finote Selam hospitals, Northwest Ethiopia: a retrospective cohort study. BMC Nutrition. 2017;3(1):42.

23. Wagnew F. Survival and predictors of mortality among under-five children with severe acute malnutrition admitted to University of Gondar Comprehensive Specialized Hospital, Northwest Ethiopia. A retrospective follow-up study; 2017.

24. Hoy D, Brooks P, Woolf A, Blyth F, March L, Bain C, Baker P, Smith E, Buchbinder R. Assessing risk of bias in prevalence studies: modification of an existing tool and evidence of interrater agreement. J Clin Epidemiol. 2012;65(9):934-9.

25. Higgins JP, Thompson SG, Deeks JJ, Altman DG. Measuring inconsistency in meta-analyses. BMJ. 2003;327(7414):557-60.

26. Borenstein $M$, Hedges LV, Higgins J, Rothstein HR. A basic introduction to fixed-effect and random-effects models for meta-analysis. Res Synth Methods. 2010;1(2):97-111.

27. Begg CB, Mazumdar M. Operating characteristics of a rank correlation test for publication bias. Biometrics. 1994;50(4):1088-101.

28. Moher D, Shamseer L, Clarke M, Ghersi D, Liberati A, Petticrew M, Shekelle P, Stewart LA. Preferred reporting items for systematic review and metaanalysis protocols (PRISMA-P) 2015 statement. Syst Rev. 2015;4(1):1.

29. Amberbir A, Woldemichael K, Getachew S, Girma B, Deribe K. Predictors of adherence to antiretroviral therapy among HIV-infected persons: a prospective study in Southwest Ethiopia. BMC Public Health. 2008;8(1):265.

30. Asena TF, Teni DA. Bayesian semi-parametric regression analysis of childhood malnutrition in Gamo Gofa zone: the social and economic impact of child under nutrition. Am J Theor Appl Stat. 2015;4(4):269-76.

31. Banbeta A, Seyoum D, Belachew T, Birlie B, Getachew Y. Modeling time-tocure from severe acute malnutrition: application of various parametric frailty models. Arch Public Health. 2015;73(1):6.

32. Boltena SS. Factors affecting the rehabilitation outcome (of outpatient therapeutic program) of children with severe acute malnutrition in Durame. Southern Ethiopia: UWC; 2008.

33. Briend A, Collins S. Therapeutic nutrition for children with severe acute malnutrition: summary of African experience. Indian Pediatr. 2010;47(8):655-9 Springer.

34. Tagar E, Sundaram M, Condliffe K, Matatiyo B, Chimbwandira F, Chilima B, Mwanamanga R, Moyo C, Chitah BM, Nyemazi JP. Multi-country analysis of treatment costs for HIV/AIDS (MATCH): facility-level ART unit cost analysis in Ethiopia, Malawi, Rwanda, South Africa and Zambia. PLoS One. 2014;9(11):e108304.

35. Tekeste A, Wondafrash M, Azene G, Deribe K. Cost effectiveness of community-based and in-patient therapeutic feeding programs to treat severe acute malnutrition in Ethiopia. Cost Eff Resour Alloc. 2012;10(1):4.

36. Wirth JP, Matji J, Woodruff BA, Chamois S, Getahun Z, White JM, Rohner F. Scale up of nutrition and health programs in Ethiopia and their overlap with reductions in child stunting. Matern Child Nutr. 2017;13(2):e12318.

37. Dereje N. Determinants of severe acute malnutrition among under five children in Shashogo Woreda, southern Ethiopia: a community based matched case control study. J Nutr Food Sci. 2014;4(300):2.

38. Kabalo MY, Seifu CN. Treatment outcomes of severe acute malnutrition in children treated within Outpatient Therapeutic Program (OTP) at Wolaita Zone, Southern Ethiopia: retrospective cross-sectional study. J Health Popul Nutr. 2017;36(1):7

39. Massa D, Woldemichael K, Tsehayneh B, Tesfay A. Treatment outcome of severe acute malnutrition and determinants of survival in northern Ethiopia: a prospective cohort study. Int J Nutr and Metab. 2016;8(3):12-23.

40. Mengesha MM, Deyessa N, Tegegne BS, Dessie Y. Treatment outcome and factors affecting time to recovery in children with severe acute malnutrition treated at outpatient therapeutic care program. Glob Health Action. 2016; 9(1):30704.

41. Saaka M, Osman SM, Amponsem A, Ziem JB, Abdul-Mumin A, Akanbong P, Yirkyio E, Yakubu E, Ervin S. Treatment outcome of severe acute malnutrition cases at the tamale teaching hospital. J Nutr Metab. 2015;2015. https://www.hindawi.com/journals/jnme/2015/641784/abs/.

42. Shanka N, Lemma S, Abyu D. Recovery rate and determinants in treatment of children with severe acute malnutrition using outpatient therapeutic feeding program in Kamba District. South West Ethiopia: Journal of Nutritional Disorders \& Therapy; 2015.

43. Shiferaw W, Tilahun B, Patrick K, Belachew T. Treatment outcome and predictors of severe acute malnutrition using the WHO guideline at a referral Hospital in Southern Ethiopia. Ethiop J Pediatr Child Health. 2015;11(1):29-37.

44. Tadesse E, Ekström E-C, Berhane $Y$. Challenges in implementing the integrated community-based outpatient therapeutic program for severely malnourished children in rural southern Ethiopia. Nutrients. 2016;8(5):251.

45. Yebyo HG, Kendall C, Nigusse D, Lemma W. Outpatient therapeutic feeding program outcomes and determinants in treatment of severe acute malnutrition in Tigray, northern Ethiopia: a retrospective cohort study. PLoS One. 2013;8(6):e65840.

46. Yorra DT, Sagar G: Survival rate and determinants in treatment of children with severe acute malnutrition using outpatient therapeutic feeding program in Sidama zone, South Ethiopia.

47. Landis JR, Koch GG. The measurement of observer agreement for categorical data. biometrics. 1977;33(1):159-74.

48. Jarso H, Workicho A, Alemseged F. Survival status and predictors of mortality in severely malnourished children admitted to Jimma University specialized hospital from 2010 to 2012, Jimma, Ethiopia: a retrospective longitudinal study. BMC Pediatr. 2015;15(1):1.

49. Kabeta A, Bekele G. Factors associated with treatment outcomes of under-five children with severe acute malnutrition admitted to therapeutic feeding unit of Yirgalem hospital. Clinics Mother Child Health. 2017;14(261):2.

50. al BTe: co-morbidity and predictors of time to recovery among under-five childen with severe acute malnutrition in Debrebrhan hospital. 2018.

51. Amsalu S, Asnakew G. The outcome of severe malnutrition in Northwest Ethiopia: retrospective analysis of admissions. Ethiop Med J. 2006;44(2):151-7.

52. Ashagrie Terefe Abeje1 TWG, Yewunetu Dessalegn Malefia3 and Birhanu Boru Befftu3: Analysis of Hospital Records on Treatment Outcome of Severe Acute Malnutrition: The Case of Gondar University Tertiary Hospital Pediatrics \& Therapeutics 2016.

53. M A: Managment outcome of severe acute malnutrition from 6 months to 5 years of age children admitted to yekatit 12 hospital. 2014.

54. Tadele Girum Adal MK, Tariku B. Incidence and predictors of mortality among severe acute malnourished under five children admitted to Dilla University Referal hospital: a retrospective longitudinal study. J Biol, Agriculture and Healthcare. 2016;6(13). https://iiste.org/Journals/index.php/ JBAH/article/view/31852/0.

55. Desyibelew HD, Fekadu A, Woldie H. Recovery rate and associated factors of children age 6 to 59 months admitted with severe acute malnutrition at inpatient unit of Bahir Dar Felege Hiwot referral hospital therapeutic feeding unite, Northwest Ethiopia. PLoS One. 2017;12(2):e0171020.

56. Admasu A, Tadesse E, Moshago T, Mekonnen N. Survival status and its associated factors among under-five children admitted with complicated severe acute malnutrition in hospitals of Wolaita zone. South Ethiopia: Retrospective Cohort Study; 2017.

57. Firehiwot $M, A b d u O$. Survival status and predictors of mortality among children aged 0-59 months admitted with severe acute malnutrition in Dilchora referral hospital, Dire Dawa from September 2011 to 2015: Harmaya University. p. 2016. https://www.researchgate.net/ publication/333619337_Survival_Status_and_Predictors_of_Mortality_ among_Children_Aged_0-59_Months_Admitted_with_Severe_Acute_ Malnutrition_in_Dilchora_Referral_Hospital_Eastern_Ethiopia.

58. Gebremichael DY. Predictors of nutritional recovery time and survival status among children with severe acute malnutrition who have been managed in therapeutic feeding centers, southern Ethiopia: retrospective cohort study. BMC Public Health. 2015;15(1):1267.

59. Chane T, Oljira L, Atomesa GE, Agedew E. Treatment outcome and associated factors among under-five children with severe acute malnutrition admitted to therapeutic feeding unit in Woldia hospital, North Ethiopia. J Nutr Food Sci. 2014;4(6):1.

60. SPHERE: Sphere project: humanitarian charter and minimum standards in disaster response. 2011.

61. Maust A, Koroma AS, Abla C, Molokwu N, Ryan KN, Singh L, Manary MJ. Severe and moderate acute malnutrition can be successfully managed with an integrated protocol in Sierra Leone-4. J Nutr. 2015;145(11):2604-9.

62. Singh K, Badgaiyan N, Ranjan A, Dixit H, Kaushik A, Kushwaha K, Aguayo V. Management of children with severe acute malnutrition: experience of nutrition rehabilitation centers in Uttar Pradesh, India. Indian Pediatr. 2014;51(1):21-5.

63. Sanghvi J, Mehta S, Kumar R. Predicators for weight gain in children treated for severe acute malnutrition: a prospective study at nutritional 
rehabilitation center. ISRN pediatrics. 2014;2014. downloads.hindawi.com/ journals/isrn.pediatrics/2014/808756.pdf.

64. Irena AH, Mwambazi M, Mulenga V. Diarrhea is a major killer of children with severe acute malnutrition admitted to inpatient set-up in Lusaka, Zambia. Nutr J. 2011;10(1):110.

65. Anand K, Sundaram K, Lobo J, Kapoor S. Are diarrheal incidence and malnutrition related in under five children? A longitudinal study in an area of poor sanitary conditions. Indian Pediatr. 1994;31(8):943-8.

66. Heikens GT, Bunn J, Amadi B, Manary M, Chhagan M, Berkley JA, Rollins N, Kelly P, Adamczick C, Maitland K. Case management of HIV-infected severely malnourished children: challenges in the area of highest prevalence. Lancet. 2008;371(9620):1305-7.

67. Talbert A, Thuo N, Karisa J, Chesaro C, Ohuma E, Ignas J, Berkley JA, Toromo C, Atkinson S, Maitland K. Diarrhoea complicating severe acute malnutrition in Kenyan children: a prospective descriptive study of risk factors and outcome. PLoS One. 2012;7(6):e38321.

68. Ahmed T, Ali M, Ullah MM, Choudhury IA, Haque ME, Salam MA, Rabbani $\mathrm{GH}$, Suskind RM, Fuchs GJ. Mortality in severely malnourished children with diarrhoea and use of a standardised management protocol. Lancet. 1999; 353(9168):1919-22.

69. Amadi B, Mwiya M, Chomba E, Thomson M, Chintu C, Kelly P, Walker-Smith J. Improved nutritional recovery on an elemental diet in Zambian children with persistent diarrhoea and malnutrition. J Trop Pediatr. 2005;51(1):5-10.

70. Maitland K, Berkley JA, Shebbe M, Peshu N, English M, Newton CRC: Children with severe malnutrition: can those at highest risk of death be identified with the WHO protocol?. PLoS med 2006, 3(12):e500.

71. Sunguya B, Koola J, Atkinson S. Infection associated with severe malnutrition among hspitalised children in East Africa. Tanzania J Health Res. 2006;8(3):189.

72. Micek ST, Welch EC, Khan J, Pervez M, Doherty JA, Reichley RM, Kollef MH. Empiric combination antibiotic therapy is associated with improved outcome against sepsis due to gram-negative bacteria: a retrospective analysis. Antimicrob Agents Chemother. 2010;54(5):1742-8.

73. English M, Esamai F, Wasunna A, Were F, Ogutu B, Wamae A, Snow RW, Peshu N. Assessment of inpatient paediatric care in first referral level hospitals in 13 districts in Kenya. Lancet. 2004;363(9425):1948-53.

74. Manary M, Brewster D. Intensive nursing care of kwashiorkor in Malawi. Acta Paediatr. 2000;89(2):203-7.

75. Dalwai S, Choudhury P, Bavdekar SB, Dalal R, Kapil U, Dubey A, Ugra D, Agnani M, Sachdev H. Consensus statement of the Indian academy of pediatrics on integrated management of severe acute malnutrition. Indian Pediatr. 2013;50(4):399-404.

76. Muoneke VU, Ibekwe RC, Nebe-Agumadu HU, Ibe BC. Factors associated with mortality in under-five children with severe anemia in Ebonyi, Nigeria. Indian Pediatr. 2012;49(2):119-23.

77. Bachou H, Tumwine JK, Mwadime RK, Tylleskär T. Risk factors in hospital deaths in severely malnourished children in Kampala, Uganda. BMC Pediatr. 2006;6(1):7.

78. WHO. Guideline: Updates on the management of severe acute malnutrition in infants and children, vol. 2013. Geneva: World Health Organization; 2013. p. 6-54.

79. Argent AC, Balachandran R, Vaidyanathan B, Khan A, Kumar RK. Management of undernutrition and failure to thrive in children with congenital heart disease in low-and middle-income countries. Cardiol Young. 2017:27(S6):S22-30.

80. Deen JL, Funk M, Guevara VC, Saloojee H, Doe JY, Palmer A, Weber MW. Implementation of WHO guidelines on management of severe malnutrition in hospitals in Africa. Bull World Health Organ. 2003;81:237-45.

81. Wanzira H, Muyinda R, Lochoro P, Putoto G, Segafredo G, Wamani H, Lazzerini M. Quality of care for children with acute malnutrition at health center level in Uganda: a cross sectional study in West Nile region during the refugee crisis. BMC Health Serv Res. 2018:18(1):561.

82. Ahmed M. Managment outcome of severe acute malnutrition from 6 months to 5 years of age children admitted to yekatit 12 hospital; 2014 .

\section{Publisher's Note}

Springer Nature remains neutral with regard to jurisdictional claims in published maps and institutional affiliations.

\section{Ready to submit your research? Choose BMC and benefit from:}

- fast, convenient online submission

- thorough peer review by experienced researchers in your field

- rapid publication on acceptance

- support for research data, including large and complex data types

- gold Open Access which fosters wider collaboration and increased citations

- maximum visibility for your research: over $100 \mathrm{M}$ website views per year

At BMC, research is always in progress.

Learn more biomedcentral.com/submissions 